\title{
Evaluation of the Biological and Wound Healing Activities of Centaurea virgata Lam.
}

\author{
Halil Aksoy \\ Marmara University, Faculty of Pharmacy, Department of Biochemistry, İstanbul, Turkey. \\ Correspondence Author: Halil Aksoy \\ E-mail: aksoyhalil@yahoo.com \\ Received: $02.09 .2020 \quad$ Accepted: 10.09 .2020
}

\begin{abstract}
Objective: Plants have significant potential effects in treating wounds. Some plants are also used in traditional medicine for their wound healing properties. The aim of this study was to investigate the antioxidant and in vitro wound healing activities of Centaurea virgata.

Methods: The antioxidant activities of extracts were examined by 2,2-diphenyl-1-picryl-hydrazyl (DPPH) and 2,2-azinobis-(3-ethylbenzothiazoline6-sulphonic acid (ABTS) methods. The total phenolic content was determined using the Folin-Ciocalteu reagent (FCR) method. In addition, the antiproliferative activity of different extracts on fibroblast cells was performed by MTT method and in vitro wound healing activity of ethanol extract of $C$. virgata was determined by scratch assay.

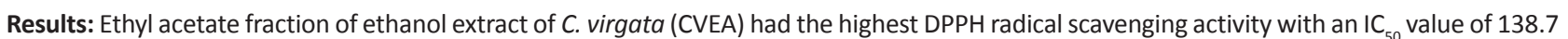
$\mu \mathrm{g} / \mathrm{mL}$. According to ABTS results, it was determined that the CVEA had a stronger radical scavenging activity than the other extracts. Hexane $(\mathrm{CVH})$ and aqueous ethanol fractions (CVAE) revealed poor antioxidant activity with $\mathrm{IC}_{50}$ values of $824.8 \mu \mathrm{g} / \mathrm{mL}$ and $610.3 \mu \mathrm{g} / \mathrm{mL}$, respectively. On the other hand, among all of the extracts analysed, it was found that phenolic content of CVEA was higher than other extracts. Except for CVAE, other extracts showed antiproliferative activity depending on the dose.
\end{abstract}

Conclusion: According to the obtained results, our finding suggests that CVAE has a migratory effect on fibroblasts and that CVAE might be a potential therapeutic agent for wound healing.

Keywords: Centaurea virgata, antioxidant activity, wound healing

\section{INTRODUCTION}

Wound healing is a collection of highly coordinated biological events consisting of three intertwining phases such as inflammation, proliferation and remodeling (1). Arachidonic acid metabolites released from thrombocytes collected in the wound area, proteases, and various growth factors contribute to the formation of the inflammation process. At the end of this phase, the number of immunologic cells begins to decrease; endothelial cells and fibroblasts emerged in the wound area and they initiate the proliferative phase (2). Within 2-3 days of injury, angiogenesis is indicated as the beginning of the proliferative phase. In angiogenesis, new blood vessels are formed from the epithelial cells to provide nutrients and oxygen for new cells. Epithelial cells proliferate into the wound areas. On the other hand, fibroblasts proliferate and differentiate into myofibroblasts. At the same time, fibroblasts secrete collagen and fibronectin to form new connective tissue (3). In the course of wound healing, keratinocytes differentiate into dermis so that the remodeling phase begins. The most important feature of this phase is the increase of collagen accumulation in the wound area (4).
Despite the great success achieved through research on the mechanism of wound healing, the development of effective therapeutics for wound healing remains a complex issue for scientists.

Plants have significant potential effects wound treatment. Also, there are reports showing that some plant species have been traditionally used by the public to treat wounds (58). Secondary metabolites found in plants such as phenolic acids, tannins, flavonoids and triterpenes are known to have wound healing activities $(5,9)$. These natural products or compounds accelerate the regeneration and healing of tissue loss through complex mechanisms. Today, many phyto-pharmacology laboratories are working extensively to isolate the active components of various medical plants and to determine their mechanism of action. The screening of herbal extracts is of great interest to scientists for the discovery of new effective drugs in the treatment of wounds. For this purpose, in vitro wound healing activity of $C$. virgata, which is used by the people for wound healing purposes, was investigated in our current study. 
The genus Centaurea, the fourth largest genus of the Asteraceae family, has about 400-700 species on the earth. They usually spread around the Middle East and east of the Northern hemisphere (10). Centaurea genus is widely distributed in Turkey. It has many medicinal properties including anti-inflammatory, antidiabetic, digestive, antipyretic, cytotoxic, anti-dandruff and antibacterial (11-13). Centaurea virgata Lam. is a species used in the traditional medicine in Turkey for the treatment of stomach pain, jaundice, headache, kidney stone and also as a diuretic and wound healing. (14). As far as we know, there is no report on the wound healing activity of $C$. virgata. Therefore, we aimed to determine in vitro antioxidant and wound healing activities of $C$. virgata in this study.

\section{MATERIAL AND METHODS}

\subsection{Plant Material Collection and Extraction}

Plant samples were collected in the flowering periods from the Çatalça district of Istanbul province of Turkey in 2010 and were identified by Dr. İsmail Şenkardeş, a botanist of the Faculty of Pharmacy, University of Marmara. Voucher specimens were deposited in the Herbarium of the Faculty of Pharmacy, Marmara University (Mare No: 22438)

Dried and ground aerial part of C. virgata (16.18 g) were extracted with $(6 \times 200 \mathrm{~mL}) \mathrm{EtOH}$, using an ultrasonic bath. After filtration and evaporation, the ethanol extract (CVE) was dissolved in $30 \mathrm{~mL} 60 \%$ aqueous ethanol, and subjected to solvent-solvent partition between $\mathrm{n}$-hexane $(5 \times 50 \mathrm{~mL})$, chloroform $(3 \times 50 \mathrm{~mL})$, and ethyl acetate $(2 \times 50 \mathrm{~mL})$. The n-hexane, chloroform, ethyl acetate and aqueous ethanol fractions of ethanol extracts of $C$. virgata obtained by this method were coded as CVH, CVC, CVEA and CVAE, respectively. All extracts were stored under refrigeration for further analysis.

\subsection{2,2-diphenyl-1-picryl-hydrazyl (DPPH) Radical Scavenging Activity}

Free radical scavenging capacity of $C$. virgata extracts were evaluated according to the previously reported procedure using the stable DPPH (15). Briefly, $10 \mu \mathrm{L}$ of extracts in DMSO at different concentrations $(250-0,048 \mu \mathrm{g} / \mathrm{mL})$ were added to $190 \mu \mathrm{L}$ methanol solution of DPPH $(0,1 \mathrm{mM})$ in a well of 96-well plate. The mixture was shaken vigorously and allowed to stand in the dark at room temperature for $30 \mathrm{~min}$. Absorbance readings were taken at $517 \mathrm{~nm}$. The percent radical scavenging activity of extracts and standard against DPPH were calculated according to the following:

DPPH radical-scavenging activity $(\%)=\left[\left(A_{0}-A_{1}\right) / A_{0}\right] \times 100$

where $A_{0}$ is the absorbance of the control (containing all reagents except the test compounds), and $A_{1}$ is the absorbance of the extracts/standard. Extract concentration providing $50 \%$ inhibition $\left(\mathrm{IC}_{50}\right)$ was calculated from the graph plotting inhibition percentage against extracts concentration. Tests were carried out in triplicate. Butylated hydroxyanisole (BHA), ascorbic acid and trolox were used as positive control.

\subsection{2,2-azinobis-(3-ethylbenzothiazoline-6-sulphonic acid (ABTS) Radical Scavenging Activity}

Free radical scavenging capacity of $C$. virgata extracts were evaluated according to the previously reported procedure (15). ABTS radical cations were prepared by mixing equal volume of $A B T S$ ( $7 \mathrm{mM}$ in $\mathrm{H}_{2} \mathrm{O}$ ) and potassium persulfate ( $4.9 \mathrm{mM}$ in $\mathrm{H}_{2} \mathrm{O}$ ), allowing them to react for $12-16 \mathrm{~h}$ at room temperature in the dark. Then, ABTS radical solution was diluted with $96 \%$ ethanol to an absorbance of about 0.7 at $734 \mathrm{~nm} .10 \mu \mathrm{L}$ of extracts in DMSO at different concentrations $(250-0.048 \mu \mathrm{g} / \mathrm{mL})$ were added to $190 \mu \mathrm{L}$ of ABTS radical solution in a well of 96-well plate. The mixture was shaken vigorously and allowed to stand in the dark at room temperature for $30 \mathrm{~min}$. Absorbance readings were taken at $734 \mathrm{~nm}$. The percent radical scavenging activity of extracts and standard against ABTS were calculated according to the following:

ABTS radical-scavenging activity $(\%)=\left[\left(A_{0}-A_{1}\right) / A_{0}\right] \times 100$

where $A_{0}$ is the absorbance of the control (containing all reagents except the test compounds), and $A_{1}$ is the absorbance of the extracts/standard. Extract concentration providing $50 \%$ inhibition $\left(\mathrm{IC}_{50}\right.$ ) was calculated from the graph plotting inhibition percentage against extracts concentration. Tests were carried out in triplicate. BHA, ascorbic acid and trolox were used as positive control.

\subsection{Determination of Total Phenolic Content (TPC)}

Total phenolic content of $C$. virgata extracts was measured using Folin-Ciocalteau reagent (16). The assay was adapted to the 96 well microplate format. $10 \mu \mathrm{L}$ of extracts in various concentrations $(151.52-18.94 \mu \mathrm{g} / \mathrm{mL})$ were mixed with $20 \mu \mathrm{L}$ Folin-Ciocalteu reagent (Sigma), $200 \mu \mathrm{L}$ of $\mathrm{H}_{2} \mathrm{O}$, and $100 \mu \mathrm{L}$ of $15 \% \mathrm{Na}_{2} \mathrm{CO}_{3}$, and the absorbance was measured at 765 $\mathrm{nm}$ after $2 \mathrm{~h}$ incubation at room temperature. Gallic acid was used as a standard and the total phenolic content was expressed as 'mg gallic acid equivalent (GAE)/g extract'.

\subsection{In-vitro Fibroblast Cell Proliferation Assay}

The effects of plant extracts on fibroblast cell proliferation were determined by MTT method. The test samples were prepared by dissolving extracts in DMSO and followed by dilution with supplemented DMEM medium to obtain the final concentration of the extracts of $C$. virgata $(10,25,50$, 100 and $200 \mu \mathrm{g} / \mathrm{mL}$, respectively). Briefly, NIH3T3 fibroblasts were seeded at $1 \times 10^{4}$ cells/well into 96 -well plate in DMEM containing $10 \%$ FBS. The final DMSO concentration in the assay was $0.1 \%$. After $48 \mathrm{~h}$, cells were exposed to five different concentrations $(10-200 \mu \mathrm{g} / \mathrm{mL})$ of plant extracts and were then incubated for $48 \mathrm{~h}$ at $37^{\circ} \mathrm{C}$ in a humidified atmosphere containing $5 \% \mathrm{CO}_{2}$. The MTT solution $(5 \mathrm{mg} / \mathrm{mL}$ ) was added directly to the each well and the plate was then incubated at $37^{\circ} \mathrm{C}$ for $4 \mathrm{~h}$. At the end of the incubation, $100 \mu \mathrm{L}$ SDS was added to each well and then incubated for another 12 $\mathrm{h}$ solubilize the formazan formed in the viable cells. The absorbance of the samples was measured at $570 \mathrm{~nm}$ using 
a microplate reader The percentage of cell proliferation was calculated and compared to a negative control.

\subsection{Scratch Assay}

Briefly, NIH3T3 fibroblasts were seeded at $5 \times 10^{4}$ cells/well in DMEM containing $10 \% \mathrm{FBS}$ were seeded into each well of 24 well plate and incubated at $37^{\circ} \mathrm{C}$ with $5 \% \mathrm{CO}_{2}$. After the confluent monolayer of NIH3T3 fibroblasts was formed, two horizontal scratches were generated using a sterile pipette tip of $100 \mu \mathrm{L}$ in each well. Any cellular debris was removed by washing with PBS and replaced with $1 \mathrm{~mL}$ of fresh medium in the absence or presence of plant extracts. Photographs were taken as two views on the left and right of each well at 10x magnification using a microphotograph (Olympus CK2, Japan) on day 0 ; then, plates were incubated at $37^{\circ} \mathrm{C}$ with $5 \%$ $\mathrm{CO}_{2}$ and photographs were taken at $24 \mathrm{~h}$.

\section{RESULTS}

The DPPH and ABTS radical scavenging activity results are shown in Table 1 as comparable with known antioxidants such as ascorbic acid, trolox and BHA. CVEA had the highest DPPH radical scavenging activity with an $\mathrm{IC}_{50}$ value of 138.7 $\mu \mathrm{g} / \mathrm{mL}$. On the other hand, $\mathrm{CVH}$ and CVAE revealed a poor antioxidant activity with $\mathrm{IC}_{50}$ values of $827.8 \mu \mathrm{g} / \mathrm{mL}$ and 610.3 $\mu \mathrm{g} / \mathrm{mL}$, respectively. When the results obtained from ABTS radical scavenging activity were evaluated, it was determined that the CVEA had stronger radical scavenging activity than the other extracts. Similarly, $\mathrm{CVH}$ had the lowest radical scavenging activities.

Table 1. Antioxidant Activities of Various Extracts Obtained From Different Parts of Centaurea virgata $(n=3)$.

\begin{tabular}{|c|c|c|}
\hline $\begin{array}{l}\text { Extracts*/ } \\
\text { Standards }\end{array}$ & $\begin{array}{l}\text { DPPH radical } \\
\text { scavenging activity } \\
\mathrm{IC}_{50}\left(\mu \mathrm{g} \cdot \mathrm{mL}^{-1}\right) \\
\text { Mean } \pm \mathrm{SD}\end{array}$ & $\begin{array}{c}\text { ABTS radical scavenging } \\
\text { activity } \\
\mathrm{IC}_{50}\left(\mu \mathrm{g} \cdot \mathrm{mL}^{-1}\right) \\
\text { Mean } \pm \mathrm{SD}\end{array}$ \\
\hline CVE & $200.3 \pm 1.49$ & $240.5 \pm 1.70$ \\
\hline CVH & $827.8 \pm 13.72$ & $487.4 \pm 3.11$ \\
\hline CVC & $293.2 \pm 1.74$ & $234.6 \pm 0.57$ \\
\hline CVEA & $138.7 \pm 2.48$ & $72.89 \pm 0.44$ \\
\hline CVAE & $610.3 \pm 12.8$ & $288.8 \pm 2.12$ \\
\hline Ascorbic acid & $17.6 \pm 0.37$ & $14.5 \pm 0.32$ \\
\hline Trolox & $14.54 \pm 0.18$ & $13.00 \pm 0.21$ \\
\hline BHA & $57.15 \pm 0.09$ & $17.06 \pm 0.58$ \\
\hline
\end{tabular}

*SD: standard deviation; CVE, CVH, CHC, CVEA, CVAE show the ethanol extract and its $n$-hexane, chloroform, ethyl acetate, and aqueous ethanol fractions of the leaves of Centaurea virgata, respectively. BHA: Butylated hydroxyanisole.

Table 2 presents total phenolic contents obtained for all the C. virgata extracts. Among all of the extracts analysed, it was found that phenolic content of CVEA was higher than that of the other extracts. While the content for CVH could not be determined, it was revealed that the CVAE extract had very low phenolic content.
Table 2. Total Phenolic Contents of Various Extracts Obtained From C. virgata.

\begin{tabular}{|c|c|}
\hline Extracts* & $\begin{array}{c}\text { TPC } \\
\text { (mg GAE/g extract)** }\end{array}$ \\
\hline CVE & 23.83 \\
\hline CVH & - \\
\hline CVC & 24.05 \\
\hline CVEA & 51.30 \\
\hline CVAE & 2.88 \\
\hline
\end{tabular}

${ }^{*} \mathrm{CVE}, \mathrm{CVH}, \mathrm{CHC}, \mathrm{CVEA}, \mathrm{CVAE}$ show the ethanol extracts and its $n$-hexane, chloroform, ethyl acetate, and aqueous ethanol fractions of the leaves of Centaurea virgata, respectively. ${ }^{* *}$ Results were expressed as gallic acid equivalent (GAE). -: could not be determined.

MTT results revealed that CVC had the highest cytotoxic effect on NIH3T3 cells with an IC $\mathrm{C}_{50}$ value of $23.07 \mu \mathrm{g} / \mathrm{mL}$ (Table 3). Except for CVAE, other extracts also showed cytotoxic effects depending on the dose.

Table 3. The Proliferative Effect of Extracts on NIH3T3 Cells.

\begin{tabular}{lllllll} 
Extracts & $\mathbf{2 0 0} \boldsymbol{\mu g}$ & $\mathbf{1 0 0} \boldsymbol{\mu g}$ & $\mathbf{5 0} \boldsymbol{\mu g}$ & $\mathbf{2 5} \boldsymbol{\mu g}$ & $\mathbf{1 0} \boldsymbol{\mu g}$ & IC50 $(\boldsymbol{\mu g})$ \\
\cline { 2 - 6 } & \multicolumn{6}{c}{$\%$ Proliferation } \\
CVEA & 33.41 & 43.9 & 61.04 & 80.91 & 110.91 & 96.8 \\
CVE & 20.67 & 31.4 & 49.57 & 73.05 & 114.94 & 65.31 \\
\hline CVAE & 95.06 & 95.79 & 97.4 & 104.8 & 107.8 & 4517.25 \\
CVC & 18.96 & 19.15 & 37.93 & 53.29 & 72.68 & 23.07 \\
CVH & 53.9 & 66.1 & 77.68 & 88.7 & 89.09 & 393.8
\end{tabular}

${ }^{*} \mathrm{CVE}, \mathrm{CVH}, \mathrm{CHC}, \mathrm{CVEA}, \mathrm{CVAE}$ show the ethanol extract and its n-hexane, chloroform, ethyl acetate, and aqueous ethanol fractions of the leaves of Centaurea virgata, respectively.

As a result of MTT analysis, wound healing experiments were studied with this extract since it was determined that only CVAE had no cytotoxic effect on the NIH3T3 cells. Depending on the dose, it was determined that CVAE increased the migration of fibroblasts in the scratch assay (Figure 1 ).

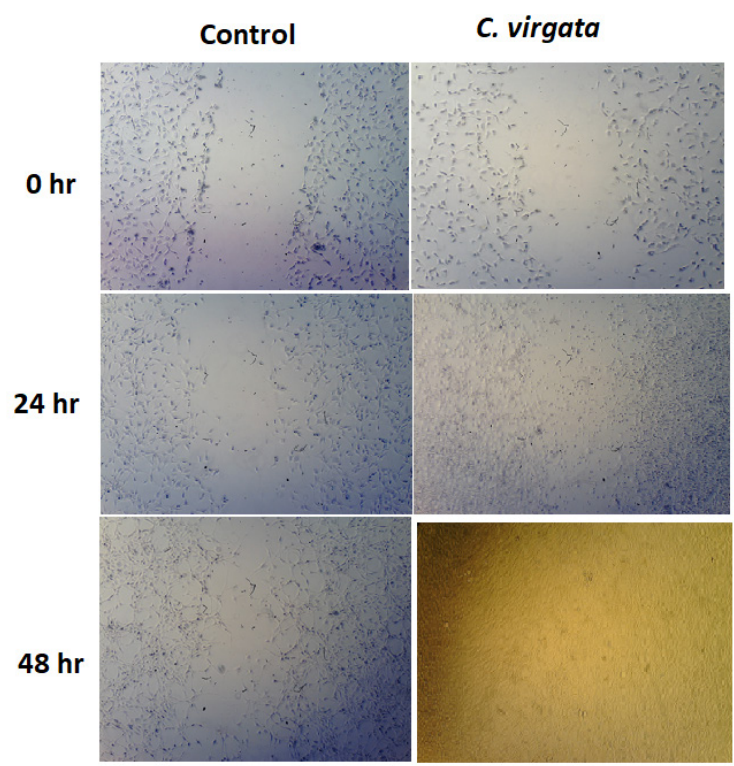

Figure 1. CVAE promoted the migration and wound closure of NIH3T3 cells in a wound scratch assay. 


\section{DISCUSSION}

Plants have rich medical value and sources of molecules with potential wound-healing activity due to the phytochemical compounds they contain. Today, plant extracts are seen as an effective alternative for wound healing due to their widespread availability $(8,17,18)$. In the current study, in vitro wound healing activity of $C$. virgata was revealed for the first time.

Wound healing is a rather complicated repair mechanism that begins after injury. Inflammation during the healing process leads to reactive oxygen species (ROS) formation, which is known for its harmful effects. The wound healing improving effects of various plant extracts can be attributed to the antioxidant and antimicrobial properties of the phytocomponents (17). Studies have shown a positive role between the free radical scavenging effect and the wound healing process.

Dermal fibroblasts are defense cells that respond to injury. Proliferation and migration of fibroblasts to the wound site are important events in the wound healing process. It is a useful model for stimulating fibroblast cell growth and studying wound healing activity in vitro. Therefore, isolation of active compounds found in natural products that affect migration of fibroblasts can help improve cutaneous wound healing. It has been reported that flavonoids, tannins, saponins and terpenoids in plants show wound healing activity by stimulating the growth of fibroblasts $(19,20)$.

Interestingly, CVC exhibited the highest antiproliferative effect on fibroblast cells depending on the dose. Studies have shown that $C$. virgata predominantly contained flavonoids such as apigenin and eupatorin (21). In activity studies with apigenin, it has been found that it inhibited osteoblastogenesis and osteoclastogenesis (22). In addition, apigenin and its derivatives are known to have antiproliferative activity (23). Similarly, various studies have shown that eupatorin has an antiproliferative effect (24). Tüzün et al (2017) reported that the chloroform extract of $C$. virgata predominantly contained apigenin and eupatorin flavonoids. In line with this study, in our study CVC showed the highest antiproliferative effect (25).

CVAE, in particular, promoted the growth of fibroblasts at concentrations of 10 and $25 \mu \mathrm{g} / \mathrm{mL}$. This mitogenic effect is a positive event for the wound healing process because fibroblasts are important cells involved in wound contraction and ECM production.

In our study, we determined that none of the extracts had significant antioxidant activity. Morever, the obtained results for DPPH are in agreement with the phenol contents determined for each sample. The low antioxidant activities of these extracts might be attributable to their low phenolic contents.

In a study performed by Keser et al. (2020), it was demostrated that C. virgata ethanol extract at concentration of $500 \mu \mathrm{g} /$ $\mathrm{mL}$ had antioxidant activity with percent inhibition values of $70.15 \%$ and $57.24 \%$ against ABTS and DPPH radicals, respectively. (21). When we compared these results with our current study, CVE with $\mathrm{IC}_{50}$ values of $200.3 \mu \mathrm{g} / \mathrm{mL}$ and $240.5 \mathrm{\mu g} / \mathrm{mL}$ showed a better antioxidant activity. These differences in the antioxidant activity of $C$. virgata may be due to the fact that different parts of the plant have been studied and/or different extraction methods have been used.

\section{CONCLUSION}

According to the obtained results, our finding suggests that CVAE has a migratory effect on fibroblasts and that CVAE might be a potential therapeutic agent for wound healing. It is also reported in the literature that a Centaurea species, C. Iycopifolia, is used by public for wound healing purposes (26). This information supports the wound healing activity of the aqueous ethanol extract of $C$. virgata which have found in our current study. However, it is necessary to isolate the active compounds responsible for the activity in order to understand the mechanism of action. Also, our results corroborate the use of $C$. virgata in traditional medicine as an wound healing.

\section{Conflict of Interest}

The author declares no conflict of interest.

\section{Acknowledgements}

The author would like to thank Dr. İsmail Şenkardeş for his help in identification of the plant materials.

\section{REFERENCES}

[1] Aksoy H, Özakpınar OB. Yara iyileşmesi ve oksidatif stres. Marmara Pharm J 2014; 18:153-158 (In Turkish).

[2] Aksoy H, Apikoglu-Rabus S, Uras F, Savcı N, Alatlı C, Erseven G, Emekli N. Evaluation of the effect of fibrin glue prepared from single-donor plasma on wound healing in rats. Hacettepe Univ J Fac Pharm 2009; 29(2): 83-93.

[3] Guo S, Dipietro LA. Factors affecting wound healing. J Dent Res 2010; 89(3):219-29.

[4] Schreier T, Degen E, Baschong W. Fibroblast migration and proliferation during in vitro wound healing. A quantitative comparison between various growth factors and a low molecular weight blood dialysate used in the clinic to normalize impaired wound healing. Res Exp Med (Berl) 1993; 193(4):195-205.

[5] Aksoy H, Sen A, Sancar M, Sekerler T, Akakin D, Bitis L, Uras F, Kultur S, Izzettin FV. Ethanol extract of Cotinus coggygria leaves accelerates wound healing process in diabetic rats. Pharm Biol 2016; 54(11):2732-2736.

[6] Aslam MS, Ahmad MS, Mamat AS, Ahmad MZ, Salam F. Antioxidant and wound healing activity of polyherbal fractions of Clinacanthus nutans and Elephantopus scaber. Evid Based Complement Alternat Med 2016; 4685246.

[7] Chin CY, Jalil J, Ng PY, Ng SF. Development and formulation of Moringa oleifera standardised leaf extract film dressing 
for wound healing application. J Ethnopharmacol 2018; 15(212):188-199.

[8] Aksoy H, Demirbağ Ç, Şen A, Şekerler T, Özakpınar Ö, Şener A, Sarfraz A, Tetik S. Evaluation of biochemical parameters in Rubus tereticaulis treated rats and its implications in wound healing. Mol Cell Biochem. 2020; 472(1-2):67-78.

[9] Aksoy H, Çevik Ö, Şen A, Göğer F, Şekerler T, Şener A. Effect of Horse-chestnut seed extract on matrix metalloproteinase-1 and -9 during diabetic wound healing. J Food Biochem 2019; 43(3):e12758.

[10] Garcia-Jacas N, Susanna A, Mozaffarian V, Ilarslan R. The natural delimitation of Centaurea (Asteraceae: Cardueae): ITS sequence analysis of the Centaurea jacea group. Plant Systematics and Evol 2000; 223(3):185-199.

[11] Köse YB, İşcan G, Demirci B, Başer KHC, Çelik S. Antimicrobial activity of the essential oil of Centaurea aladagensis. Fitoterapia 2007; 78 (3):253-254.

[12] Ozsoy N, Kultur S, Yilmaz-Ozden T, Celik BO, Can A, Melikoglu G. Antioxidant, anti-inflammatory, acetylcholinesterase inhibitory and antimicrobial activities of Turkish endemic Centaurea antiochia var.praealta. J Food Biochem 2015; 39(6):771-776.

[13] Yirtici U, Goger F, Sarimahmut M, Ergene A. Cytotoxic and apoptotic effects of endemic Centaurea fenzlii Reichardt on the MCF-7 breast cancer cell line. Turk J Biol 2017; 41(2):370377.

[14] Tuzlacı E. Türkiye Bitkileri Geleneksel Illaç Rehberi (Turkey's Plants Traditional Medicine Guide). 1. Baskı. İstanbul: İstanbul Tıp Kitabevleri; 2016 (In Turkish).

[15] Zou Y, Chang SK, Gu Y, Qian SY. Antioxidant activity and phenolic compositions of lentil (Lens culinaris var. morton) extract and its fractions. J Agric Food Chem 2011; 59(6):2268-2276.

[16] Ozsoy N, Can A, Yanardağ R, Akev N. Antioxidant activity of Smilax excelsa $L$. leaf extracts. Food Chem 2008; 110(3):571583.

[17] Raina R, Parwez S, Verma PK, Pankaj NK. Medicinal plants and their role in wound healing. Vet Scan 2008; 3(1):21-26.
[18] Kumarasamyraja D, Jeganathan NS, Manavalan R. A review on medicinal plants with potential wound healing activity. Int J Pharma Sci 2012; 2(4):105-111.

[19] Syarina PN, Karthivashan G, Abas F, Arulselvan P, Fakurazi S. Wound healing potential of Spirulina platensis extracts on human dermal fibroblast cells. EXCLI J 2015; 2(14):385-393.

[20] Pitz Hda S, Pereira A, Blasius MB, Voytena AP, Affonso RC, Fanan S, Trevisan AC, Ribeiro-do-Valle RM, Maraschin M. In vitro evaluation of the antioxidant activity and wound healing properties of Jaboticaba (Plinia peruviana) fruit peel hydroalcoholic extract. Oxid Med Cell Longev 2016; 3403586.

[21] Keser S, Keser F, Türkoğlu I, Kaygılı Ö, Tekin S, Demir E, Karatepe M, Yılmaz Ö, Kırbağ S, Sandal S, Türkoğlu S. In vitro biological evaluation and phytochemical contents of three Centaurea $L$. species growing from Eastern Anatolia in Turkey. KSU J Agric Nat 2020; 23(1):148-156.

[22] Goto T, Hagiwara K, Shirai N, Yoshida K, Hagiwara H. Apigenin inhibits osteoblastogenesis and osteoclastogenesis and prevents bone loss in ovariectomized mice. Cytotechnology 2015; 67(2):357-365.

[23] Csapi B, Hajdú Z, Zupkó I, Berényi A, Forgo P, Szabó P, Hohmann J. Bioactivity-guided isolation of antiproliferative compounds from Centaurea arenaria. Phytother Res 2010; 24(11):16641669.

[24] Androutsopoulos V, Arroo RR, Hall JF, Surichan S, Potter GA. Antiproliferative and cytostatic effects of the natural product eupatorin on MDA-MB-468 human breast cancer cells due to CYP1-mediated metabolism. Breast Cancer Res 2008; 10(3):R39.

[25] Tuzun BS, Hajdu Z, Orban-Gyapai O, Zomborszki ZP, Jedlinszki N, Forgo P, Kivcak B, Hohmann J. Isolation of chemical constituents of Centaurea virgata Lam. and xanthine oxidase inhibitory activity of the plant extract and compounds. Med Chem 2017; 13(5):498-502.

[26] Demirci S, Özhatay N. An ethnobotanical study in Kahramanmaraş (Turkey); Wild plants used for medicinal purpose in Andırın, Kahramanmaraş, Turk J Pharm Sci 2012; 9 (1):75-92. 